\title{
Use of Laryngeal Mask Airway in the Management of a Difficult Airway: A Case Report
}

\author{
Elizabeth Ogboli-Nwasor ${ }^{1}$, Ahmad Tijjani Lawal ${ }^{2}$ \\ ${ }^{1}$ Department of Anaesthesia, Ahmadu Bello University (ABU), Teaching Hospital, Zaria, Nigeria; ${ }^{2}$ Department of Surgery, Ahmadu \\ Bello University (ABU), Teaching Hospital, Zaria, Nigeria. \\ Email: drnwasor@yahoo.com
}

Received January $21^{\text {st }}, 2013$; revised February $27^{\text {th }}$, 2013; accepted March $11^{\text {th }}, 2013$

\begin{abstract}
Background: Difficulty in management of the airway occurs most frequently in patients who have Mallampati grade III and IV, and other unfavourable airway findings like short neck, restriction in range of motion of the temporomandibular joints and inadequate neck flexion and extension. Because of unavailability of fibreoptic bronchoscopes or inexperience in their use, laryngeal mask airway (LMA) has become a common and acceptable airway management option. This is a case report of a postmenopausal woman who had her airway managed with LMA following initial failed intubation necessitating a rescheduling of the operation. Result: The patient had a successful surgery and postoperative recovery was uneventful. Conclusion: The LMA is a useful option in the management of an anticipated or unexpected difficult airway, especially in resource-poor settings where fibreoptic bronchoscopes may not be readily available.
\end{abstract}

Keywords: Laryngeal Mask Airway; Anticipated Difficult Airway

\section{Introduction}

A difficult airway could be anticipated or unexpected [1]. Difficulties or failures in airway management still remain important factors in morbidity and mortality related to anaesthesia and intensive care [2].

Findings in a preoperative airway assessment may be related to the presence of a difficult airway. This is based upon the recognized associations between the difficult airway and a variety of airway characteristics [3].

The LMA allows ventilation and oxygenation, although it does not completely protect the airway against aspiration [2]. The use of LMA represents a major advance in airway management and has been incorporated into the algorithm for management of the difficult airway, provided the patient does not have obvious periglottic pathology [2,4]. Even though fibreoptic intubation remains the preferred choice of many anaesthesiologists, the LMA and its various modifications provide equal or better conditions for intubation when compared to the awake fibreoptic technique. It also provides a better safety profile in the emergency scenario [5].

\section{Case Report}

Mrs I. D., a 45 -year-old Para $5^{+1}$ post-menopausal civil servant presented to the surgical outpatient department of our health facility with 5-year history of a left breast lump and a year history of low back pain. No risk factor for breast cancer was established. A histological diagnosis of invasive ductal carcinoma was made following an incisional biopsy. She was subsequently worked up for modified radical mastectomy.

Pre-anaesthetic review revealed a previous history, 5 months ago, of failed intubation and delayed recovery from anaesthesia. The patient was obese with a BMI of 34.6, had facial hirsutism, normal chest findings and a blood pressure of $150 / 90 \mathrm{mmHg}$. Airway assessment revealed a short neck, thyromental distance of $6.4 \mathrm{~cm}$ and Mallampati III. Available investigations were normal.

The first time the operation was scheduled, the patient was intubated with difficulty using endotracheal tube (ETT) size 7.5. The tube was however dislodged while it was being secured. Further single attempts at intubation failed and the operation was cancelled and surgery rescheduled for the next available elective list. An updated pre-anaesthetic review included a note on anticipation of a difficult airway. The alternative airway management plan was to intubate using a McCoy laryngoscope or fibreoptic bronchoscope. The laryngeal mask airway (LMA) was to be used in the absence or failure of the above two options. Patient was counselled and reassured. She was brought to the theatre 2 weeks later, and 3 attempts were made to intubate her which eventfully failed (ETT sizes 7.5, 7.0 and 6.5). After suctioning of the oropharynx, a size 4 LMA was subsequently inserted, with ease. The LMA was well tolerated with the patient main- 
taining oxygen saturation at 98\%. Recovery from anaesthesia was uneventful. She was taken back to the ward and was subsequently discharged to the surgical outpatient department.

\section{Discussion}

The LMA is a supraglottic airway device developed by British anaesthesiologist, Dr. Archie Brain. It has been in use since 1988. Initially designed for use in the theatre for elective ventilation, the LMA has more recently come into use in the emergency setting as an important accessory device for management of the difficult airway [6]. This is because it is easy to use and quick to insert even for the inexperienced provider [6]. The role of the LMA both in the American Society of Anaesthesiologists (ASA) algorithm on management of the difficult airway and airway management in general has become more clearly defined [2]. While fibreoptic intubation remains the preferred choice of many anaesthesiologists, the LMA and its modifications provide equal or better conditions for intubation when compared with the awake fibreoptic technique. The ProSeal LMA with its better safety profile is proving valuable in the emergency scenario [7]. Also the use of fibreoptic intubation is limited by its nonavailability, lack of adequate experience with and contraindications to its use.

The LMA is shaped like a large endotracheal tube on the proximal end which connects to an elliptical mask on the distal end. It is designed to sit in the patient's hypopharynx and cover the supraglottic structures, thereby allowing relative isolation of the trachea [6]. Several types of LMA are in existence [1,6]. The LMA Classic is the original reusable design (Figure 1(a)). Others are LMA Unique (a disposable version), LMA Flexible, reinforced LMA (Figure 1(b)), LMA ProSeal (Figure 1(c)), LMA Fastrach (an intubating LMA) (Figure 1(d)), LMA Supreme and LMA CTrach. The size ranges are as below:

1: Infant; 2: Child; 2 1/2: Child; 3: Small adult; 4: Normal adult; 5: Larger adult.

The technique for insertion of the standard LMA involves first suppressing the patient's reflexes to a level similar to that required for the insertion of an oropharyngeal airway to prevent coughing or laryngospasm, then proceeding as below:

1) The cuff is deflated and mask lightly lubricated (Figure 2(a)).

2) A head tilt is performed, the patient's mouth opened fully and the tip of the mask inserted along the hard palate with the open side facing but not touching the tongue (Figure 2(b)).

3) The mask is inserted further, using the index finger to provide support for the tube (Figure 2(c)). Eventually, resistance will be felt at the point where the tip of the mask lies at the lower oesophageal sphincter (Figure 2(d)).

4) The cuff is now inflated using an air-filled syringe attached to the valve at the end of the pilot tube (Figure 2(e)).

5) The LMA is secured either by a length of bandage or adhesive strapping attached to the protruding tube.

6) A "bite block" may be necessary to reduce the risk of damage to the LMA at recovery [8]. The technique for LMA insertion in children is shown in Figure 3.

The following considerations should be borne in mind

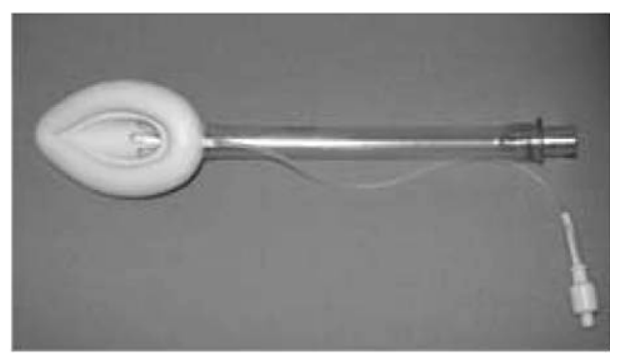

(a)

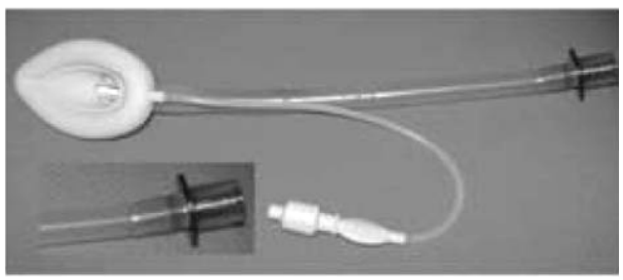

(b)

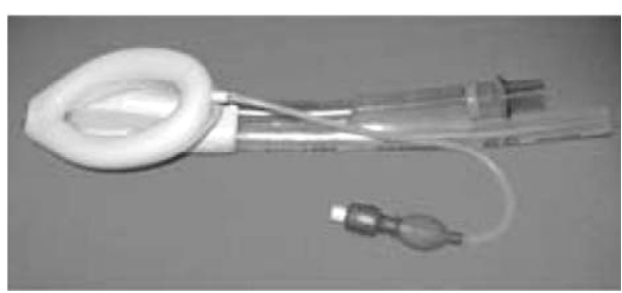

(c)

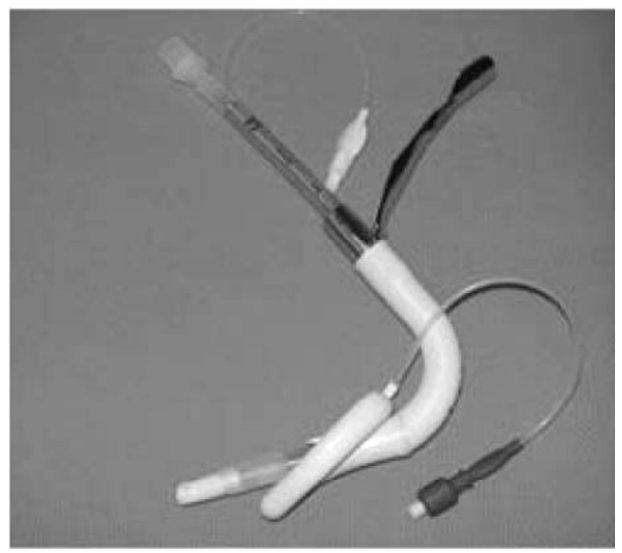

Figure 1. The standard LMA and its various modifications. from lecture notes on clinical anaesthesia $\left(2^{\text {nd }}\right.$ ed., by Gwinnutt CL). 


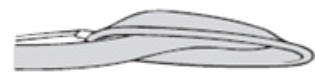

(a)

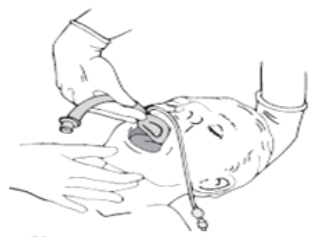

(b)

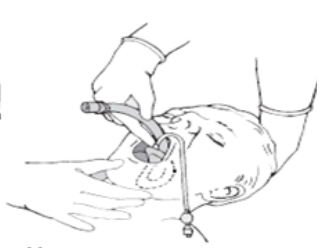

(c)
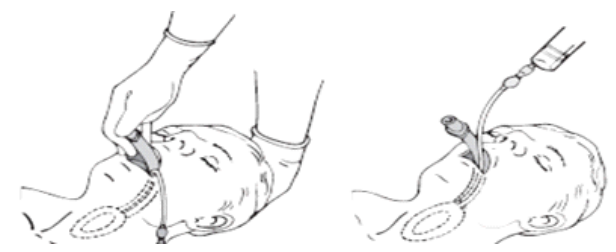

Figure 2. Technique for insertion of the LMA from lecture notes on clinical anaesthesia $\left(2^{\text {nd }}\right.$ ed., by Gwinnutt $\left.C L\right)$.

when using the LMA:

- Insertion is easier following propofol induction than sodium thiopentone induction because propofol has better suppression of laryngeal reflexes [9].

- Can be used for both spontaneous and controlled ventilation.

- Can be removed with patient light or deep.

- A "bite block" is required to protect the airway from destruction [8].

Use of LMA is indicated in:

- Elective ventilation as an alternative to facemask ventilation or for short procedures.

- The management of difficult airway; as a rescue device before the onset of a “can't intubate can't ventilate” (CICV) scenario or as an interim measure while preparing for a surgical airway in a CICV situation.

- Cardiac arrest.

- As a conduit for intubation.

- Prehospital airway management [6]. Its use is absolutely contraindicated when:

- Patient cannot open mouth.

- There is complete upper airway obstruction.

Relative contraindications to use of LMA include when there is;

- Increased risk of regurgitation and aspiration of gastric contents.

- Suspected or known abnormalities in the supraglottic anatomy.

- $\quad$ Need for high airway pressure $[6,10]$.

This patient was a clear case of anticipated difficult airway going by the past history of failed intubation and airway assessment findings of short neck and receding chin in an obese patient. McCoy laryngoscope and fibreoptic bronchoscope were not available for use. Thus she will have been saved the complications of repeated conventional laryngoscopy and offered the benefits of use of LMA on an elective basis rather than as a rescue device.

When used correctly, laryngeal mask airway is a life saver. Our report is similar to the two cases reported by Onyekwulu et al. [11] wherein it was used for rescue airway management and as a ventilatory device during anaesthesia. The anaesthetic management of patients with burns and sub mental contractures also present a special challenge to the intubation skills of the anaesthetist. The case reported by Jasper [12] also demonstrated the useful role played by Laryngeal Mask in the management of difficult airway with particular reference to patients with face and neck burns.

Table 1 shows the advantages and disadvantages of laryngeal mask airway and fibreoptic bronchoscopy in airway management during difficult airway situations [13]. The technique for fibreoptic bronchoscopy in a child is shown in Figure 4.

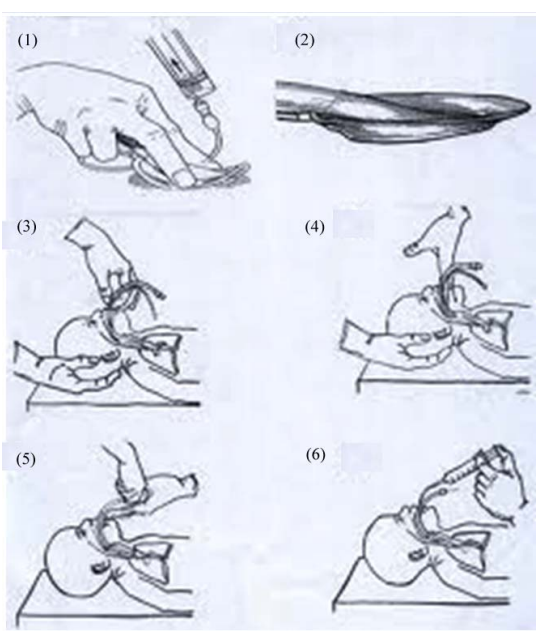

Figure 3. Technique of LMA insertion in children.

Table 1. The advantages and disadvantages of LMA and fibreoptic intubation.

\begin{tabular}{ccc}
\hline Characteristic & LMA & Fiberscope \\
\hline Avoidance of laryngoscopy & ++++ & ++ \\
Avoidance of esophageal intubation & ++++ & ++ \\
Ease of placement & +++ & + \\
Allows ventilation without intubation & ++++ & 0 \\
Patient tolerance & +++ & ++ \\
Cardiovascular/sympathetic response & +++ & +++ \\
Aspiration risk & +++ & ++ \\
PPV requirement & ++ & $\mathrm{NA}$ \\
Security of airway & +++ & $\mathrm{NA}$ \\
Pediatric use & ++++ & + \\
Anesthetic depth & ++++ & ++ \\
Learning curve & +++ & ++ \\
\hline
\end{tabular}

Abbreviations: LMA, Laryngeal Mask Airway; NA, not applicable; PPV, positive pressure ventilation [13]. 


\section{Conclusion}

We conclude that with careful patient assessment and case selection the LMA can be effectively used to safely manage cases of difficult airway and thus prevent disas- trous outcome. Therefore every anaesthetist should be familiar with the use of this device. Further studies are required to confirm the widespread use of LMA in difficult airway situations especially in resource-poor settings.

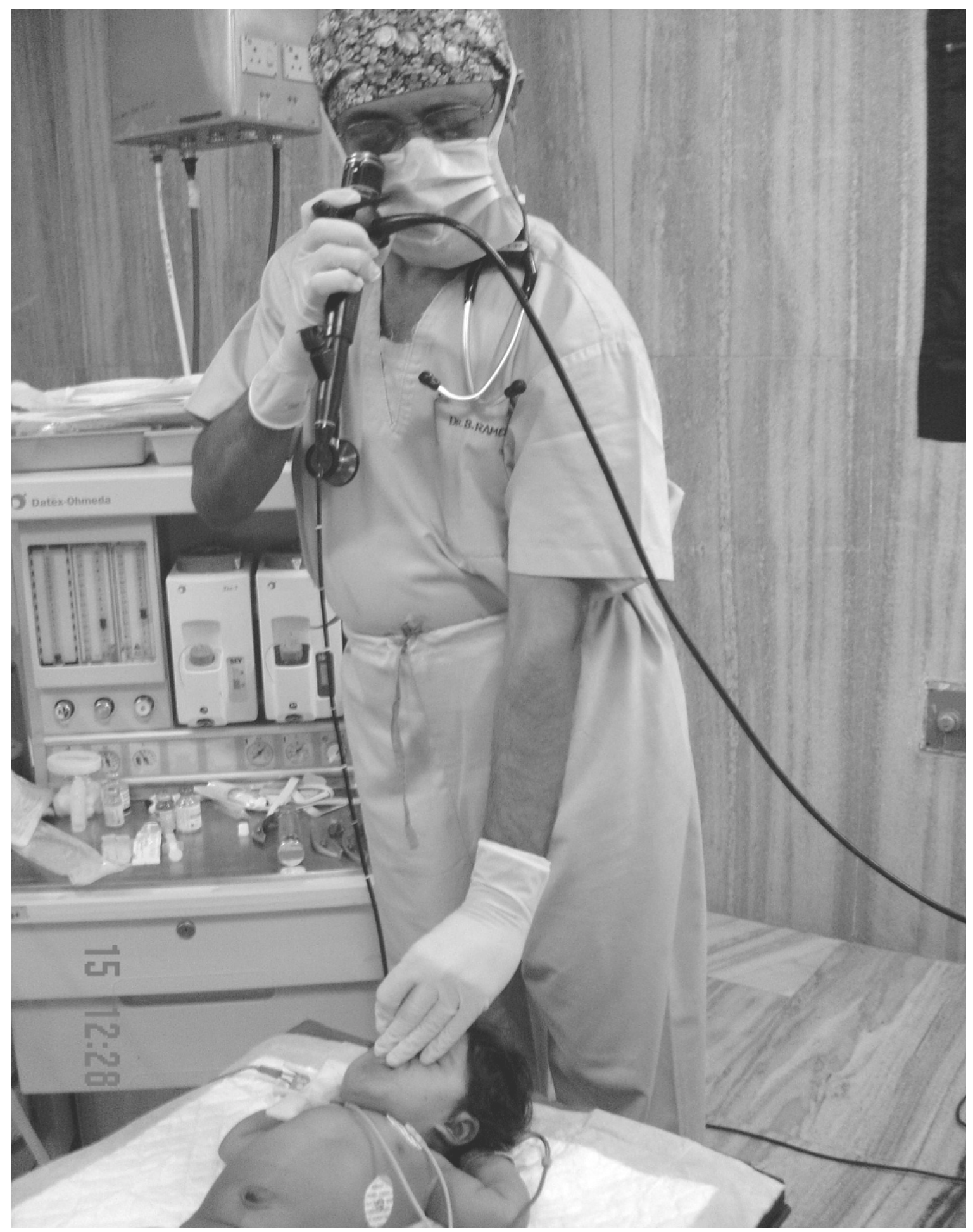

Figure 4. Fibreoptic intubation in a child. Source Ramesh S. Fibreoptic airway management in adults and children Indian J. Anaesth 2005; Vol. 49, No. 4, pp. 293-299. 


\section{REFERENCES}

[1] C. Pinnock, T. Lin, T. Smith and R. Jones, "Fundamentals of Anaesthesia,” 2nd Edition, Greenwich Medical Media Ltd., London, 2003.

[2] American Society of Anaesthesiologists, "Laryngeal Mask Airway and the ASA Difficult Airway Algorithm," American Society of Anaesthesiologists, Inc., Manhattan, 1998.

[3] American Society of Anaesthesiologists, "Practice Guidelines for Management of the Difficult Airway,” American Society of Anaesthesiologists, Inc., Manhattan, 2002.

[4] O. Langeron, J. Amour, B. Vivien and F. Aubrun, "Clinical Review: Management of Difficult Airways,” Critical Care, 2006. http://ccforum.com/content/10/6/243

[5] J. J. Henderson, M. T. Popat, I. P. Latto and A. C. Pearce, "Difficult Airway Society Guidelines for Management of the Unanticipated Difficult Intubation,” Anaesthesia, Vol. 59, No. 7, 2004, pp. 675-694. doi:10.1111/j.1365-2044.2004.03831.x

[6] N. Bosson and P. E. Gordon, "Tracheal Intubation, Laryngeal Mask Airways,” 2009.

[7] K. Ramachandran and K. Santhanagopalan, "Laryngeal Mask Airway and the Difficult Airway," Current Opinion in Anaesthesiology, Vol. 17, No. 6, 2004, pp. 491-493. doi:10.1097/00001503-200412000-00007

[8] C. L. Gwinnutt, "Lecture Notes: Clinical Anaesthesia," 2nd Edition, Blackwell Publishing Ltd., Malden, 2004.

[9] S. M. Yentis, N. P. Hirsch, G. B. Smith and A.-Z. Anaesthesia, "An Encyclopaedia of Principles and Practice," Butterworth-Heinemann Ltd., Oxford, 1993.

[10] A. R. Aitkenhead, "The Operating Theatre Environment," In: A. R. Aitkenhead and G. Smith, Eds., Textbook of Anaesthesia, 4th Edition, Churchill Livingstone, Edinburgh, 2002, pp. 409-416.

[11] F. A. Onyekwulu and A. Nwosu, "Emergency Airway Management with Laryngeal Mask Airway,” Nigerian Journal of Clinical Practice, Vol. 14, No. 1, 2011, pp. 95-97. doi:10.4103/1119-3077.79269

[12] O. A. Jasper, “Anaesthetic Management of Post-Burn Contractures, a Recurrent Challenge from Oil Pipeline Vandalization in Nigeria: A Case Report," Cases Journal, Vol. 2, 2009, p. 9141. doi:10.1186/1757-1626-2-9141

[13] C. V. Pollack Jr., "The Laryngeal Mask Airway: A Comprehensive Review for the Emergency Physician,” The Journal of Emergency Medicine, Vol. 20, No. 1, 2001, pp. 53-66. doi:10.1016/S0736-4679(00)00273-0 